\title{
Community engagement strategy for healthy diet in urban community: A phenomenological study
}

\author{
Kusumaningrum Fitrina ${ }^{1,2^{*}}$, Baiquni Fahmi $^{1,2}$, and Supriyati Supriyati ${ }^{1}$ \\ ${ }^{1}$ Department of Health Behavior, Environment and Social Medicine, Faculty of Medicine, Public Health and Nursing, Universitas \\ Gadjah Mada, Jl. Farmako, Sekip Utara, Yogyakarta 55281 Indonesia \\ ${ }^{2}$ Center for Health Behavior and Promotion, Faculty of Medicine, Public Health and Nursing, Universitas Gadjah Mada, Jl. Farmako \\ Sekip Utara, Yogyakarta 55281 Indonesia
}

\begin{abstract}
Unhealthy diet is the risk factors for non-communicable diseases with limited intervention in Indonesia. Environmental change interventions are known to be effective in encouraging changes in healthy diet. However, community engagement is needed to ensure the adoption of the behaviour. This study seeks to identify the strategy to engage urban community in healthy diet intervention. Qualitative research with phenomenological approach was conducted in Yogyakarta, Indonesia. Samples were selected among citizens of Yogyakarta city with the age range from $19 \mathrm{yr}$ old to $65 \mathrm{yr}$ old. The informants consist of lay persons, cadres and stakeholders. Data from 87 respondents were collected through 7 focus group discussions and 2 in-depth interviews. Strategies to engage community in healthy eating interventions consists of 3 main themes: i) intervention's characteristics, ii) information characteristics and iii) the information channel. The intervention's expected characteristics are aimed at various ages, using family approach through stakeholder support and collaboration and by increasing cadre's capacity and providing opportunity to manage funding. Information characteristics are accessible, valid, up to date and personal. Information can be disseminated through virtual and non-virtual media. Community engagement strategies in healthy eating interventions should be segmented, strengthening the role of family and easily accessible.
\end{abstract}

\section{Introduction}

An unhealthy diet is one of the risk factors of noncommunicable disease with limited intervention in Indonesia $[1,2]$. Data from Indonesia Basic Health Research 2018 showed only $4.6 \%$ of the population consumed fruits and vegetables as recommended by World Health Organization (WHO) [3]. Even though WHO had recommended best buy interventions for noncommunicable disease prevention, best buy interventions regarding healthy diet have not been implemented thoroughly in Indonesia [4].

In Indonesia, encouraging healthy diet possess a great challenge because of the diverse cultural background and socioeconomic status (SES) of it's community. Age, gender, SES, ethnicity and also the type of region determine the dietarry pattern in Indonesia [5, 6]. Understanding the community's preferences is important to encourage healthy diet especially in the community with lower SES7. Theorydriven community-based intervention which targeted environmental change showed promising results in improving healthy eating behaviour [8-12].

Community engagement is an action to involve community in the whole process of intervention $[13,14]$. Intervention which prioritizes community engagement tend to be effective especially for the disadvantaged community. One of the main principles of community engagement is ensuring shared-decision making between authority/stakeholders and community $[15,16]$. Community engagement can be improved through collective decision-making, training, and ensuring cash flow stability [13].

Some nutrition intervention in Indonesia had implemented community engagement strategy through workshop and cadre's involvement [17]. However, intervention conducted in the urban community tends to result in limited community participation because of the lack of social capital and high social inequality $[18,19]$. With these challenges, various strategies of community engagement should be identified to gain understanding on factors that support community engagement in health program in urban community [20].

\section{Subjects and methods}

This is a qualitative research with phenomenological approach to explain phenomena in society using community perspectives [21]. Using the phenomenological approach, this study aims to describe participants' experiences in implementing healthy eating behaviour and identify strategies that might be developed to help participants adopt healthy eating behaviour.

\footnotetext{
* Corresponding author: fitrina.mahardani.k@mail.ugm.ac.id
} 


\subsection{Participants}

Participants in this study were selected purposively using maximum variation sampling which meet inclusion criteria: i) citizen of Yogyakarta city for at least six months prior to the study and ii) age $19-65$ years old. Variations that were used consist of SES (high and low), age range (18 - 35, 36 - 55 and 56+) and gender (men and women). Socioeconomic status was determined using the type of occupation and amount of salary. Respondents with high SES were those who worked with salary above the regional minimum wage standard (IDR 1572200 in 2017). Respondents with low SES were those who did not work or those who worked with salary below the regional minimum wage standard. Lists of 615 community association/neighbourhood (rukun warga/RW) in Yogyakarta city were developed and divided by the characteristics of SES of its community. Eight community association/neighbourhood were chosen through discussion with district health office. Local leader in the neighbourhood/community association were involved in the process of selecting participants. Before participating in this study, the local leader explained the study objectives and explored the willingness to participate in this study. Total participants in this study were 87 respondents consist of main participants (lay persons, local leaders and cadres) $(\mathrm{n}=$ 79) and stakeholders $(n=8)$. Stakeholders who participated in this study consist of primary health care providers $(n=6)$ and head of health promotion section of District Health Office, Yogyakarta City $(\mathrm{n}=1)$ and head of division of food security of Department of Agriculture, Yogyakarta City $(\mathrm{n}=1)$. Detail of the distribution of main participants was available on Table 1 .

Table 1. Characteristics of main participants

\begin{tabular}{|c|c|c|}
\hline Characteristics & $\mathbf{n}$ & $\%$ \\
\hline \multicolumn{3}{|l|}{ Age } \\
\hline - $\quad 18$ to 35 & 23 & 29.11 \\
\hline$-\quad 36$ o 55 & 42 & 53.16 \\
\hline$-56+$ & 14 & 17.72 \\
\hline \multicolumn{3}{|l|}{ Gender } \\
\hline - Male & 24 & 30.38 \\
\hline - Female & 55 & 69.62 \\
\hline \multicolumn{3}{|c|}{ Social Economic Status (SES) } \\
\hline - Low & 39 & 49.37 \\
\hline - High & 40 & 50.63 \\
\hline
\end{tabular}

\subsection{Setting}

The study was conducted in Yogyakarta city, Special Region of Yogyakarta, Indonesia. Yogyakarta city is an urban area in the Special Region of Yogyakarta, Indonesia. This region has a unique character because of their culture and closeness of community. With the population up to 431939 people, Yogyakarta city has an urban characteristic but with tight community structure. Some non-communicable disease prevention programs such as smoke-free home program has been quite successfully implemented in several areas in Yogyakarta city [22].

Eight neighbourhood (rukun warga/RW) were selected which represented high level of SES and low level of SES. Data collections were held at community centre or at the house of one of participants. Data collections were conducted in three months from July to September 2017.

\subsection{Data collection}

The data were collected through nine focus group discussions and two in-depth interviews. Focus group discussions were held to obtain data from lay persons, cadres, local leaders and primary health care providers. In-depth interviews were conducted to gain the perspectives from head of health promotion section of District Health Office, Yogyakarta City and head of division of food security of Department of Agriculture, Yogyakarta City. Data collections were held once for every participant and recorded using audio recording. Data collections were guided using interview guides consisting of 7 open-ended questions about respondents' experience in practicing diet and getting involved in community-based programs about healthy lifestyle.

Focus group discussions were conducted by three personnel that took the role as facilitator/interviewer, observer and note taker. Every data collection was recorded and provided with field notes that record the observation of data collection process and every change of the procedure taken due to some circumstances during data collection. Focus group discussions were lasted about $60 \mathrm{~min}$ to $90 \mathrm{~min}$, meanwhile in-depth interviews were conducted in $60 \mathrm{~min}$ to $75 \mathrm{~min}$. Every records of data collection were transcribed, commented and analysed right after data collection. Data saturation was obtained through discussion between researchers.

\subsection{Data analysis}

Content analysis conducted by three researchers. After data collection, the audio recording was transcribed. Researcher 2 and 1 reviewed the transcribed and provided methodology, substantive and analytic comments about the data collection and the result. Transcribe was coded by researcher 3 to develop meaning units. The codes were then discussed between researchers to gain different views regarding the data. Categories that consists of close meaning units developed by researcher 1 . The developed categories were discussed between researchers to develop themes. 
Data analysis resulted in ten categories and three themes.

\subsection{Ethical consideration}

This study did not inflict any harm on the participants. The study protocol was reviewed by the review board of Faculty of Medicine, Public Health and Nursing, Universitas Gadjah Mada, Indonesia. Ethical clearance were obtained in June 2017 with the letter from ethical review board of Faculty of Medicine, Public Health and Nursing, Universitas Gadjah Mada, Indonesia no. Ref://KE/FK/0816/EC2017. Before the data collection, the researcher also provided the participants with an informed consent document containing the information regarding detail of the study aims and process, benefit and risk when participate in the study, and measures in ensuring confidentiality. All the participants approached in this study were agree to participate and signed the consent.

\section{Results}

There were 3 themes developed from this study that explain the strategy of engaging community in healthy eating programs. Those themes were i) characteristics of intervention; ii) characteristics of information and iii) information channel. Detail themes and categories were explained in Table 2.

Table 2. Strategies to engage community in healthy eating programs

\begin{tabular}{|c|c|}
\hline Theme & Categories \\
\hline $\begin{array}{l}\text { Characteristics of } \\
\text { intervention }\end{array}$ & $\begin{array}{l}\text { - Segmented to accommodate the need } \\
\text { of specific age group } \\
\text { - Implementing family approach } \\
\text { - Ensuring stakeholder collaboration } \\
\text { - Providing of stakeholder support } \\
\text { - Improve cadres/volunteers capacity } \\
\text { - Opportunity to manage funds }\end{array}$ \\
\hline $\begin{array}{l}\text { Characteristics of } \\
\text { information }\end{array}$ & $\begin{array}{l}\text { - Accessible and valid } \\
\text { - Up to date } \\
\text { - Developed according the needs of } \\
\text { individuals (personal) }\end{array}$ \\
\hline Information channel & $\begin{array}{l}\text { - Virtual (internet-based/digital) } \\
\text { - Non-virtual (community meeting, } \\
\text { face to face interaction) }\end{array}$ \\
\hline
\end{tabular}

\subsection{Characteristics of intervention}

Strategies proposed by the study participants regarding healthy eating intervention were segmented by age group, therefore the program can benefit the entire community. Participants also reflected that different age group had different need of interventions. One of the participants also highlights how elderly age group was not supposed to be the priority target of healthy eating programs because elderly had already understood the importance of healthy eating.
So, we support, need, some health educations ... and maybe the most important target (of the program) is to kids and teenagers. I think elderly had already aware (of healthy diet) Male, 36 -55 y.o, high SES

Family approach was also proposed as one of strategy in developing healthy eating programs. Our data also showed that mothers tend to prioritize the preference and needs of other family member when preparing food.

If we are mothers, we prioritize our kids first. First, of course (preparing) breakfast, before they go to school. There usually milk or fruits, then they usually go to school till noon. There usually catering from school, therefore we usually may prepare (food) for dinner Female, 36 - 55 y.o, low SES

Stakeholder also viewed by our main participants as the important party to deliver healthy diet program. Stakeholders that were identified include local leader, primary health care providers and district health office staffs. Participants were expecting stakeholders support and collaboration in cadre's training, provision of health information and education, funding support, provision of healthy food during community activities, provision of supplementary feeding, local regulation, and standard of healthy eating.

Other strategies that shared by participants was the opportunity to manage funding. Some program related to healthy lifestyle in chosen neighbourhoods in this study showed that the opportunity to manage funding helps participants sustain the program. Trash bank program in one of the neighbourhood with low SES helped the community to find alternative income through adoption of healthy lifestyle.

\subsection{Characteristics of information}

Other than intervention, participants highlight the importance of health information for community. Even though some information is available in the community, that information only available for some segment of community.

\section{Healthy food, so far, we know from family welfare (pendidikan kesejahteraan keluarga/PKK) cadres, about this, about this. But (the information) usually not reached all family members. Now there are a lot of media, printed, electronic and maybe hand phone. We open it, and we know about healthy diet. But to understand and implement is hard if there are no agreement in community. - Male, $36-$ 55 y.o, high SES}

Therefore, participants propose that healthy diet information should be easily accessible, valid, up to date, and developed according to individuals' needs. Participants also propose that the health information 
should be attractive, repetitive and share some example of healthy menus but still affordable,

There were some distinct differences of information needs regarding healthy diet across ages. Young participants were more interested in diet related to body image and the effects of foods to health and body. Meanwhile, grown up participants were more interested in information regarding healthy menus and also the importance of nutrients.

\subsection{Information channel}

Most participants obtained healthy diet information from face to face discussion that delivered by cadres. Even though some participants support this method of delivery, participants experienced problems in the delivery of information, such as incomplete information and unstandardized delivery.

For young age participants, media social still become the main choice of information channel regarding healthy diet. Information delivered through media social was seen as attractive and allowed creativity to be shared.

\section{I choose (information delivered through) media social. But not those that read and then forgotten. I mean like 'onthel', make a creative idea. We are more attracted ... to the weird content-Female, 18-35, low SES}

\section{Discussions}

This study showed that healthy diet programs should be delivered with various methods to ensure the needs from all segment of the community are fulfilled and improve community engagement. Program to overcome malnutrition in Kupang Indonesia showed that tailored community mobilisation through workshop and cadre's involvement can improve the outcome of the program [17]. Evidence also showed that health promotion intervention that used more than one intervention method and used the environmental change approach would be effective in changing behavior [15, 23]. However, health providers should consider the provision of policy framework and the monitoring and evaluation system to ensure community engagement $[17,24]$.

Participants in our study highlighted stakeholders role. Local leaders, primary health care providers, and district health office staff were expected to develop a supportive environment by providing cadre training, providing access to healthy food, and local regulation. However, Indonesia's nutrition policy, especially for adolescents, was very limited and lacked guidance for stakeholder coordination [25]. Improvement of stakeholder role by sharing experience with the local community and providing information is important to ensure the success of intervention [26].

Our study showed that community tend to get confused about healthy diet information. The provision of valid and trusted information are important to help community make a responsible decision regarding their health $[27,28]$. In healthy diet case, health literacy is also needed to improve community capacity to choose the appropriate nutrition for their health and utilize health care services [29]. This study also support the evidence that digital health communication were needed healthy diet program especially for younger generation [30, 31].

Engaging urban community in health intervention is still a challenging task. However, this study showed that urban community was not completely closed off. There are opportunities to reach out to those communities through community leader, cadres/volunteerism, and digital media utilization. Stakeholders still play important part in pro [viding support to develop supporting environment. Collaboration between stakeholders is the key to an effective intervention $[20,32]$.

\section{Conclusion}

Community engagement strategy for healthy diet in urban settings should acknowledge every segment of community and strengthen the role of family and stakeholders. Public health providers should also understand the health information dynamics in the digital era, improve community health literacy, and develop a creative way to engage the urban community in health programs.

This study was funded by Faculty of Medicine, Public Health and Nursing, Universitas Gadjah Mada, Indonesia in 2017

\section{References}

1. J. Schröders, S. Wall, M. Hakimi, F.S.T. Dewi, L. Weinehall, M. Nichter, et al., PLoS ONE, 12, 1-31 (2017).

2. V.M. Oddo, A. Roshita, J.H. Rah, Public Health Nutr., 22, 1, 15-27 (2019).

3. Kementrian Kesehatan RI. Laporan Nasional Riskesdas 2018. Laporan Riskesdas Nasional 2018. (2018). [In Bahasa Indonesia].

4. X.H. Zhang, L. Lisheng, N.R.C. Campbell, M.L. Niebylski, P. Nilsson, D.T. Lackland, J. Clin. Hypertens., 18, 1, 5-6 (2016).

5. Y.S. Kunto, H. Bras, Food Nutr. Bull., 40, 2, 182201 (2019).

6. T. Arjuna, S. Soenen, R.A. Hasnawati, K. Lange, I. Chapman, N.D. Luscombe-Marsh, Nutrients, 9, 11 (2017).

7. N. Darmon, A. Drewnowski, Contribution of food prices and diet cost to socioeconomic disparities in diet quality and health: A systematic review and analysis. Nutr Rev. 2015;73(10):643-60.

8. M. Gebreslassie, F. Sampaio, C. Nystrand, R. Ssegonja, I. Feldman, Prev Med (Baltim), 136, 106100 (2020). 
9. D. de Ridder, F. Kroese, C. Evers, M. Adriaanse, M. Gillebaart, Psychol. Heal., 32, 8, 907-941 (2017).

10. S. Snuggs, C. Houston-Price, K. Harvey, Appetite, 140, 114-133 (2019).

11. J. Brambila-Macias, B. Shankar, S. Capacci, M. Mazzocchi, F.J.A. Perez-Cueto, W. Verbeke, et al., Food Nutr. Bull., 32, 4, 365-375 (2011).

12. N. Bhattarai, A.T. Prevost, A.J. Wright, J. Charlton, C. Rudisill, M.C. Gulliford, BMC Public Health, 13, 1 (2013).

13. G. Brunton, J. Thomas, A. O'Mara-Eves, F. Jamal, S. Oliver, J. Kavanagh, BMC Public Health, 17, 1, 1-15 (2017).

14. D. Glandon, L. Paina, O. Alonge, D.H. Peters, S. Bennett, Health Policy Plan., 32, 10, 1457-1465 (2017).

15. A. O'Mara-Eves, G. Brunton, S. Oliver, J. Kavanagh, F. Jamal, J. Thomas, BMC Public Health. 15, 1, 1-23 (2015).

16. E. De Weger, N. Van Vooren, K.G. Luijkx, C.A. Baan, H.W. Drewes, BMC Health Serv Res., 18, 1, 1-18 (2018).

17. B.R. Bait, J.H. Rah, A. Roshita, R. Amaheka, V. Chrisnadarmani, M.R. Lino, Bull World Health Organ., 97, 9, 597-604 (2019).

18. P. Lawless, S. Pearson, Plan Theory Pract., 13, 4, 509-527 (2012).

19. N. Alicea-Alvarez, K. Reeves, M.S. Lucas, D. Huang, M. Ortiz, T. Burroughs, et al., J. Urban Heal., 93, 4, 732-743 (2016).

20. Y. Xue, A. Temeljotov-Salaj, A. Engebø, J. Lohne, J. Clean Prod. 268, 122291 (2020).

21. J.W. Creswell, C.N. Poth, Qualitative inquiry and research design: Choosing among five approaches, Sage publications (2016).

22. R. Padmawati, Y. Prabandari, T. Istiyani, M. Nichter, M. Nichter, Tob. Prev. Cessat., 1-10 (2018).

23. A. Snelling, Introduction to Health Promotion, San Francisco, CA: John Wiley \& Sons, Ltd. (2014).

24. I. Irmansyah, H. Susanti, K. James, K. Lovell, S. Idaiani, S. Imah, et al., BMC Psychiatry, 20, 1, 115 (2020).

25. D.D. Soekarjo, A. Roshita, A.M. Thow, M. Li, J.H. Rah, Food Nutr. Bull., 39, 3, 475-486 (2018).

26. C. Ganter, A. Aftosmes-Tobio, E. Chuang, R.E. Blaine, T. Land, K.K. Davidson, J. Community Heal., 41, 2, 305-314 (2016).

27. W. Jacobs, A.O. Amuta, K.C. Jeon, Cogent. Soc. Sci., 3, 1 (2017).

28. B.W. Hesse, D.E. Nelson, G.L. Kreps, R.T. Croyle, N.K. Arora, B.K. Rimer, et al. Arch. Intern. Med., 165, 22, 2618 (2005).

29. L.K. Bartholomew, G.S. Parcel, G. Kok, N.H. Gottlieb, Planning Health Promotion Programs: An Intervention Mapping Approach, San Francisco, CA: Jossey-Bass (2006), p. 13-15.
30. R. McCarroll, H. Eyles, C. Ni Mhurchu, Prev. Med. (Baltim), 105, 156-168 (2017).

31. T. Rose, M. Barker, C. Jacob, L. Morrison, Europe PMC, 61, 6, 669-677 (2018).

32. M.T. Garcia, S.M. Ribeiro, A.C.C.G. Germani, C.M. Bógus, Public Health Nutr., 21, 2, 416-425 (2018). 